\title{
Gulf War syndrome: an emerging threat or a piece of history?
}

\author{
N Greenberg and S Wessely
}

King's College London, Department of Academic Psychological Medicine, Academic Centre for Defence Mental Health, London, UK.

\author{
Correspondence \\ Professor S Wessely, King's College \\ London, Department of Academic \\ Psychological Medicine, Academic \\ Centre for Defence Mental Health, \\ Weston Education Centre, \\ Cutcombe Road, London SE5 9RJ, \\ UK. \\ E-mail: \\ Simon.Wessely@iop.kcl.ac.uk
}

Received 12 March 2008

Revised 18 June 2008

Accepted 15 July 2008

\begin{abstract}
'Gulf War syndrome' is a phrase coined after the 1991 Gulf War to group together disparate, unexplained health symptoms in Gulf veterans. This paper examines the many hypotheses that have been put forward about the origins of the concept and gives an overview of the studies that have attempted to explain the lasting health effects associated with Gulf service. Our review finds that although in the UK there has not yet been evidence of a new Gulf War syndrome as a result of the current conflicts in Iraq and Afghanistan, there is a rise in post-conflict psychiatric disorders now being reported in the USA. We postulate that after conflicts military personnel will always face some form of post-conflict syndrome and the nature of the threats experienced is likely to dictate the form the syndrome might take. We also postulate that media reporting is likely to have influenced and to continue unhelpfully to influence the health of service personnel.
\end{abstract}

\section{Introduction}

In 1991, a coalition of troops liberated Kuwait from the control of Iraqi forces. The war-fighting phase of the 1991 conflict was short and associated with minimal casualties to Coalition forces. Initially, the conflict was a medical success story, not only in terms of the low number of battle casualties but also the minimal burden of heat-related or infectious diseases, traditionally a major source of both morbidity and mortality for service personnel in operations carried out in testing environments.

However, just a few months after the war, media reports of first an apparent, but never confirmed, cluster of birth defects $^{1}$ in the children of some Gulf veterans, and later of unexplained health symptoms in other Gulf veterans began to emerge. These reports began in the USA but gradually spread to nearly all the countries that had taken part in the coalition against Saddam Hussein, with the possible exception of Saudi Arabia. Finally, and it is unclear exactly when or by whom, the term 'Gulf War syndrome' (GWS) was coined to group these disparate phenomena together.

The nature and existence of GWS have been and continue to be the subject of heated debates, even though more of the recent attention has switched to the latest conflict in Iraq. This article reviews the origins of GWS and the numerous explanations of its nature, and compares the research carried out on veterans of the Gulf War with that on veterans of the ongoing conflicts in Iraq. It also considers the nature of future psychological challenges that may affect service personnel currently conducting operational duties around the world.

\section{The beginnings of a 'GWS'}

In August 1990, Iraqi forces invaded and occupied Kuwait. The international community responded by convening a coalition military force derived from the USA $(697,000$ troops committed), the UK $(53,500$ troops), France $(25,000$ troops) and over 30 other nations, including Saudi Arabia, Denmark, Canada, and Australia.

After five weeks of intense bombardment of Iraqi positions, the ground war began on 24 February 1991 and lasted only four days. It was a resounding military success, and a triumph for military medical services. Traditionally, offensive operations are associated with large numbers of disease non-battle injury casualties from causes such as heat illness. However, in the 1991 Gulf War there were no deaths from disease non-battle injuries among US or British troops. ${ }^{2}$ Yet death is not the only important, or indeed media-worthy, outcome, as the GWS story showed in a powerful way.

\section{The initial reports}

The first media reports of unusual illnesses occurring in Gulf War veterans began to emerge from the USA towards the end

This is an Open Access article distributed under the terms of the Creative Commons Attribution licence which permits unrestricted use, distribution, and open - access reproduction in any medium, provided the original work is properly cited. 
of 1991 (Facing Persian Gulf syndrome. Philadelphia Inquirer, 1993). Initial stories tended to focus on two health concerns: unusual illnesses in previously fit veterans and an increase in birth defects in veterans' children. Understandably, there was considerable public interest and the media responded by increasing their coverage of the issue. It remains unclear who coined the term 'GWS', but considerable media and public pressure led to both the USA, and subsequently, the UK, conducting epidemiological research.

\section{The first studies}

The first response was to set up disease registers that enabled Gulf veterans to attend a clinic and undergo a comprehensive health assessment. These began in the USA with the establishment of the Department of Defense and Veterans Affairs Health Examination Registry Program. The UK followed with the Gulf War Veterans Medical Assessment Programme. More than 100,000 veterans attended these programmes, more than $90 \%$ of these in the USA. ${ }^{3,4}$ Case registers such as these are not random samples of the population and caution should be applied before drawing any firm conclusions from the data derived from them. Given the numbers involved, however, these should have sufficient power to detect any major increase in a wellrecognised illness or disease or to indicate an emergent condition. Neither of these was identified in studies based on the Gulf War veteran registers, ${ }^{4}$ where the largest diagnostic category was 'medically unexplained symptoms and syndromes' ${ }^{3,5,6}$

\section{Cancer and mortality}

The media have claimed that Gulf War veterans suffered an increase in mortality rates. ${ }^{7}$ However, comprehensive analyses of the US and UK Gulf cohorts ${ }^{7}$ have not shown an increase in mortality in both groups, other than a rise in the rate of accidental death (US and UK) or suicide (US only). This observation has often been made in the aftermath of other conflicts $^{8,9}$ and is possibly linked to an increase in risktaking behaviour. Furthermore, no increase was found in cancer rates among UK or Australian veterans of the Gulf War. ${ }^{10,11}$

\section{The Gulf War health effect}

Increased rates of symptom reporting in a Gulf cohort were first picked up by an US Army study looking at reservist personnel in Indiana $^{12}$ and then confirmed by the Iowa Persian Gulf Study Group. ${ }^{13}$ Incidence of conditions such as chronic fatigue syndrome, depression, and post-traumatic stress disorder (PTSD) were all elevated. All these are based on reported symptoms rather than objective clinical markers.

The UK's first systematic epidemiological study compared 4246 randomly selected British Gulf War veterans, drawn from all three Services with similar numbers of non-deployed personnel (the so-called 'Era' group), and with an active duty control group who had served, some years later, in the

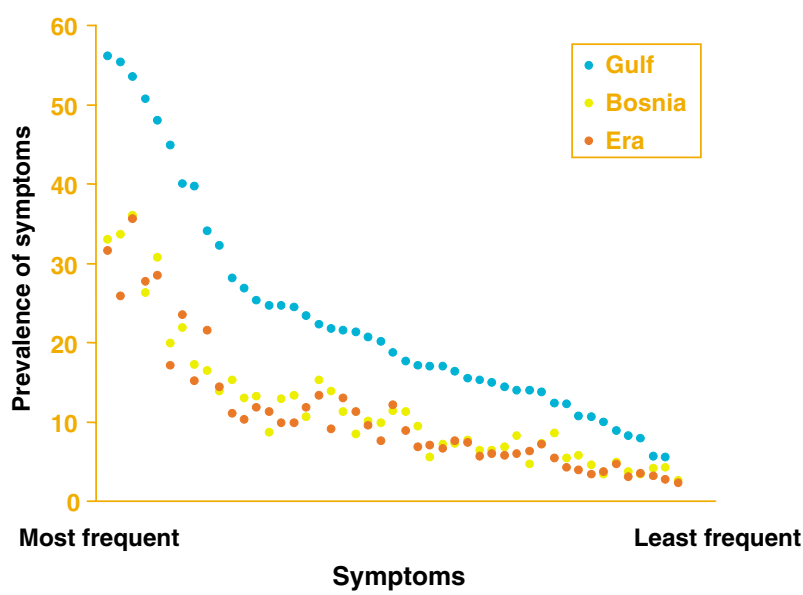

Figure 1 Graphical representation of the Gulf health effect. ${ }^{14}$ The graph represents a comparison of the three personnel groups studied by the King's College London Group. The Gulf group deployed to the War, the Era group was in the military at the time of the War but was not deployed and the Bosnia group deployed to Bosnia a few years later (representing another deployed group for comparison). To the left are common symptoms, such as fatigue or headache, whereas to the right are unusual symptoms, such as a lump in the throat, night sweats, or urinary frequency. It is clear that there is no difference between personnel deployed to Bosnia and personnel in the military in general in 1991 who did not deploy to the Gulf at that time. It is striking that the Gulf cohort is different. Of equal interest is that the shape of the curve between the Gulf and the control groups does not differ, suggesting that no specific symptom is linked with Gulf Service. Instead, personnel who were deployed to the Gulf simply report more of each and every symptom that they were asked about.

Bosnian conflict. The results showed that UK Gulf veterans were 2-3 times more likely to report each and every one of the 50 physical symptoms that were inquired about than either the Era group or the Bosnian group (Figure 1). ${ }^{14-16}$ Furthermore, although perceived health was decreased in the Gulf cohort, physical functioning was only very slightly different and still above expected non-military norms.

These are not isolated findings. ${ }^{17-19}$ A review by Barrett et al. $^{20}$ again concluded that Gulf War veterans report 2-3 times the rates of common symptoms compared with their non-deployed colleagues. Other studies have also found that health perception and quality of life are impaired in those who were deployed to the Gulf compared with military personnel who were not. ${ }^{21,22}$ Investigators did find an unexplained twofold increase in rates of seborrhoeic dermatitis, ${ }^{23}$ a result that awaits replication.

A large US study performed using multiple methods of data collection has reported 40 cases of amyotrophic lateral sclerosis (ALS). The US government considered this significant enough to declare the disease service-attributable. ${ }^{24}$ However, there remains good reason to believe that the excess is the result of an ascertainment bias, in which greater efforts were made to find cases in Gulf veterans than in control individuals, together with an unusually low rate of ALS in those control individuals. ${ }^{25,26}$ An increase in ALS has also been reported in veterans of other wars where there was no suggestion of exposure to organophosphate nerve agents, 
considered one of the possible causes for GWS. ${ }^{27}$ Furthermore, there has not been an increase in mortality owing to neurological disease in Gulf Veterans, which would be expected as ALS is ultimately fatal. ALS is still rare, fortunately, in groups of veterans and cannot explain the overall increase in symptomatology in Gulf veterans.

\section{Psychological sequelae}

The numerous studies investigating Gulf War veterans have found that many fulfilled the diagnostic criteria for depression and anxiety, as well as for chronic fatigue syndrome, multiple chemical sensitivity, and irritable bowel syndrome. Expert committees have concluded, perhaps unsurprisingly, that there is a clear association between deployment to the Gulf and a range of psychiatric and behavioural disorders. ${ }^{28}$ On the other hand, the size of the association may not be sufficient to explain all the observed ill health. In one of few studies using direct interviews, for example, we have shown that many Gulf veterans who were unwell did not fulfil the criteria for formal psychiatric disorders. ${ }^{29}$ The conclusion is that although the rate of true psychiatric disorders doubled in Gulf veterans, when compared with the absolute illness burden as a result of formal psychiatric disorders, it remains low. For example, only 3\% of our randomly chosen sample had PTSD. ${ }^{30}$ So although personnel were twice as likely to have PTSD if they went to the Gulf, ${ }^{31}$ most Gulf veterans, even those with increased levels of physical symptoms, did not have mental health disorders. Therefore, classic psychiatric disorders per se cannot account for the Gulf War health effect in its entirety.

\section{Limitations of the epidemiological studies}

Many of the better studies of the effect of service in the Gulf have used epidemiological techniques to study large samples of veterans. ${ }^{11,13,14}$ Most studies have used self-report measures and it is important to note that these tend to have a poor correlation with findings of clinical physical examination. ${ }^{32}$ For instance, when 'medically unexplained syndromes', which are characterised by symptoms very similar to those of GWS, have been investigated in the non-military samples where they are very common, fewer than one in five are found to have a discrete biomedical explanation. ${ }^{33}$ Thus, it would be misleading to assume that reporting of symptoms is closely linked with suffering from a diagnosable disease or disorder. ${ }^{34}$

Recall and participant biases are important considerations and have affected the investigation of GWS. The literature confirms that many things influence the recall of military hazards, not just what actually happened. ${ }^{35}$ A study using medical records of a group that supposedly prepared for deployment to the Gulf but did not actually deploy showed that less than $1 \%$ of those who recalled having received a biological warfare vaccine had done so. ${ }^{36}$ What can never be controlled for is that personnel who were in the Gulf will always remember that they were there. As such, participant bias is likely to have a role and those who were deployed may be more likely to attribute their symptoms to their Gulf deployment. However, when we asked currently serving personnel about health status in a different context to deployment history and then later ascertained who had served in the Gulf, the differences in health reporting between Gulf and non-Gulf personnel remained. ${ }^{37}$

\section{Is the phrase 'GWS' valid?}

There is substantial evidence to suggest that there is an identifiable Gulf health effect but that effect does not amount to a discrete disorder or indeed syndrome. To identify a GWS as a unique condition, it would be necessary to show that there was a constellation of symptoms and signs specifically related to service in the Gulf; numerous controlled studies have shown this is not the case. ${ }^{14,20}$ Furthermore, the symptoms experienced by veterans also occur elsewhere, without an association with Gulf deployment. ${ }^{38,39}$

Most scientists, but not all, share this view. Robert Haley, a US epidemiologist in Dallas, Texas, was the first to present evidence suggestive of a new syndrome ${ }^{40}$ and continues to espouse this position. However, his study was based on a single reserve battalion, failed to achieve a satisfactory response rate, but most importantly had no control group. As others have pointed out on many occasions, ${ }^{41}$ this makes it impossible to determine whether the reported constellation of symptoms is indeed unique to Gulf War veterans. Since then he has claimed evidence of first peripheral, and then later on, central nerve damage in Gulf veterans, attributable, in his view, to exposure to a combination of chemical weapons and/or pesticides. ${ }^{42,43}$ However, several expert review panels have not been convinced either by the medical evidence or the suggestion of exposure to chemical weapons. ${ }^{44,45}$ Other studies ${ }^{46,47}$ failed to find evidence of significant damage to the peripheral nervous system in Gulf veterans, making exposure to organophosphate pesticides an unlikely cause of ill health in these people. Well-conducted neuropsychological studies of central nervous system function in Gulf veterans have not shown compelling evidence of damage. ${ }^{48}$ A replication of the original neuroimaging study is keenly anticipated but if history is to be a guide, will most likely prove reassuring.

Numerous papers have shown beyond reasonable doubt that there are substantial numbers of veterans labelled with GWS who have identifiable problems; reported prevalence rates range from 20 to $30 \%{ }^{49-52}$ Furthermore, we do not consider that the reporting of symptoms is, in the main, a result of attempts to procure financial rewards. The British War Pension system does not require a formal diagnosis to award compensation, simply an opinion on the level of disability, from whatever cause. In spite of many Gulf Veterans having received monetary recompense for their disabilities, evidence suggests that most Gulf veterans who were ill in 1996 were still unwell in 2001. ${ }^{53}$

Yet whatever the inadequacies of the term, GWS has captured the popular and media imagination and is probably 
here to stay. Bowing to the inevitable, in 2005 the UK Ministry of Defence accepted the phrase GWS, for the purpose of awarding war pensions, with the caveat that the term was an umbrella term covering the various clinical presentations and outcomes. However, it is noteworthy that not all coalition allies (e.g. the French military) have come to the same view.

\section{Who is at risk?}

In general, the associations of illness in Gulf War veterans tend to be nonspecific. For example, symptoms are neither associated with any particular service nor with what an individual service person did while in the Gulf. ${ }^{54}$ Personnel in the combat or 'teeth' sections, for example, do not have elevated rates of ill health compared with others. Rank, though, is a consistent marker of ill health. Personnel of lower rank, which may be taken as a proxy for lower educational status, have a greater burden of symptoms. ${ }^{55,56}$ Several US studies report that reservists and women are at increased risk, ${ }^{52,57}$ suggesting a possible predisposition. However, again, this was not the case for UK personnel. ${ }^{14}$

\section{What are the proposed causes?}

Despite the above, a variety of agents have been alleged to be the 'cause' of GWS. In general, most of these claims have not been substantiated. For example, depleted uranium (DU), used in munitions such as tank shells, is often proposed as a possible cause of ill health in Gulf personnel. Those most likely to come into contact with DU would have been personnel working in or around armoured vehicles. But, as already discussed, there is no link between the role an individual veteran fulfilled and reporting of symptoms. Likewise, those personnel who have been injured with DU fragments, thus indisputably exposed, have not suffered adverse health consequences to date. ${ }^{58}$ Evidence from the 2003 Iraq war has also failed to link exposure to DU with health problems in Coalition forces. ${ }^{59}$

Another exposure often mentioned relates to the pyridostigmine bromide tablets that were used as a prophylactic against possible effects of exposure to some chemical weapons. However, Canada sent three ships to the Gulf, only two of which used pyridostigmine bromide prophylaxis, yet the rate of illness was the same in personnel from all three ships. ${ }^{60}$

Other putative agents include organophosphate pesticides. These were successfully used to decrease the threat of disease from insect vectors but if handled incorrectly can cause damage to the nervous system. Detailed studies of the peripheral nervous system in both US- and UK-derived samples have failed to find evidence of neuropathy and a large US epidemiological survey of Gulf veterans and their families came to the same conclusion. ${ }^{61}$

Another claim is that ill health has resulted from accidental exposure to organophosphate-based nerve agents, of which the chief culprit was sarin nerve agent that may have been released unnoticed with the destruction of the Iraqi arms dump at Khamisayah. It has also been claimed that there was a deliberate but undetected use of sarin by Iraqi forces but this has little or no military credibility. However, irrespective of whether sarin was released into the environment, expert committees have not been convinced that this could be responsible for the observed ill health, not least given the chemical doses and exposure distances involved. ${ }^{44,62}$

On the other hand, there is some epidemiological evidence linking the particular pattern of vaccinations given to protect personnel against biological warfare with subsequent ill health. The UK group from King's College London, for example, reported an association between symptomatic outcomes and receiving multiple vaccinations in general, or specific jabs against chemical and biological weapons (CWBs), such as the anthrax vaccine. However, detailed investigations have failed to confirm that this link is immunologically mediated, and the possibility that problems in record keeping (acknowledged as a major deficiency) and recall bias account for some of this association remains a real one. ${ }^{14,36,51,63}$

Other potential causative agents, including fumes from burning oil wells, ${ }^{64}$ have also been investigated but detailed environmental monitoring at the time and subsequent outcome studies ${ }^{64}$ have failed to find convincing evidence to support these or other more maverick theories. ${ }^{41}$

In the above section, we have touched on part of what is now a considerable body of literature on the proposed risks. We acknowledge that there are some who are convinced that at least one or more of these possible hazards are indeed the cause of ill health in Gulf veterans. Golomb, ${ }^{65}$ for example, has argued for some years that the combined effect of exposure to acetyl cholinesterase inhibitors, such as nerve agents, pyridostigmine bromide, and pesticides, are indeed directly causal in this context. However, a long series of authoritative and extensive reviews, such as those produced by the prestigious and independent Institute of Medicine in the United States and others, ${ }^{41,44,45,62}$ have failed to be convincing through these arguments. No compelling evidence has yet emerged implicating any hazardous substance, acting alone or in combination, in the genesis of ill health in Gulf veterans. We think it is unlikely that this position will change materially.

\section{What is the treatment and prognosis?}

There has not been a consensus on which therapies are most effective for the symptoms of GWS. Cognitive behavioural therapy has been tried, using approaches similar to that used for other medically unexplained symptoms such as chronic fatigue syndrome. In 2003, the US Department of Defense and the Veterans Administration carried out a large trial comparing cognitive behavioural therapy, graded exercise therapy, and a combination of both. The trial had 1092 symptomatic Gulf veterans. The resulting improvements were only modest, ${ }^{66}$ although it would be premature to assume that differently designed rehabilitative programmes would not achieve better success. ${ }^{67}$ 
A substantial number of Gulf War veterans continue to report poor health. Hotopf et al. ${ }^{53}$ followed up after four years a cohort of people who believed they had GWS. They remained unwell, although interestingly, the health gap between the Gulf and Era groups appeared to be narrowing.

\section{Post-conflict syndromes}

History has many examples of post-conflict ill health syndromes. ${ }^{68}$ From the middle of the nineteenth century, when interpretable medical records and accounts began to be kept, there are clinical descriptions of ex-servicemen with considerable similarities to the Gulf narratives. Their conditions have received many different labels: Soldier's Heart, later termed Effort syndrome, shell shock, neurasthenia and, more recently, Agent Orange syndrome and PTSD.

Historian Edgar Jones and colleagues conducted a systematic study of UK war pension files from the Boer War, the First and Second World Wars, and ending with clinical files from the Gulf War Medical Assessment Programme. ${ }^{69}$ The results showed that post-conflict syndromes with considerable similarities to Gulf War illness have been reported after all the major conflicts involving the British Armed Forces.

The medical literature also contains many other medically unexplained symptoms with similarities to the Gulf War health effect, examples being chronic fatigue syndrome, total allergy syndrome, dental amalgam disease, and sick building syndrome.

\section{Is there an Iraqi war syndrome?}

What light does the current conflict in the Gulf shed on the health consequences of the 1991 war, and what can we expect in the future? One lesson that was learned from the GWS saga was the necessity to conduct large-scale health surveillance and research from the outset of the deployment, rather than at a later date, when too much time had elapsed to unravel a complex chain of causality.

Mindful of the past, the UK Ministry of Defence has funded an ongoing cohort study of the health of British service personnel that was planned alongside the military preparation for the 2003 invasion of Iraq. Even larger studies are in place in the USA. The UK study, however, does have the advantage of covering all three Services, and of including not only those still serving in the Armed Forces but also those who have left. It is independent of the Armed Forces, which means it is possible to use personally identifiable data and hence permits direct follow up of personnel.

\section{The King's studies}

After Op TELIC 1, the UK code name for the 2003 invasion of Iraq, researchers at King's College London launched a cohort study $^{70}$ to monitor any possible physical or psychological health effects in members of the UK Armed Forces. The study compares those who had served on Op TELIC 1 and a single control group from the remaining members of the Armed Forces.
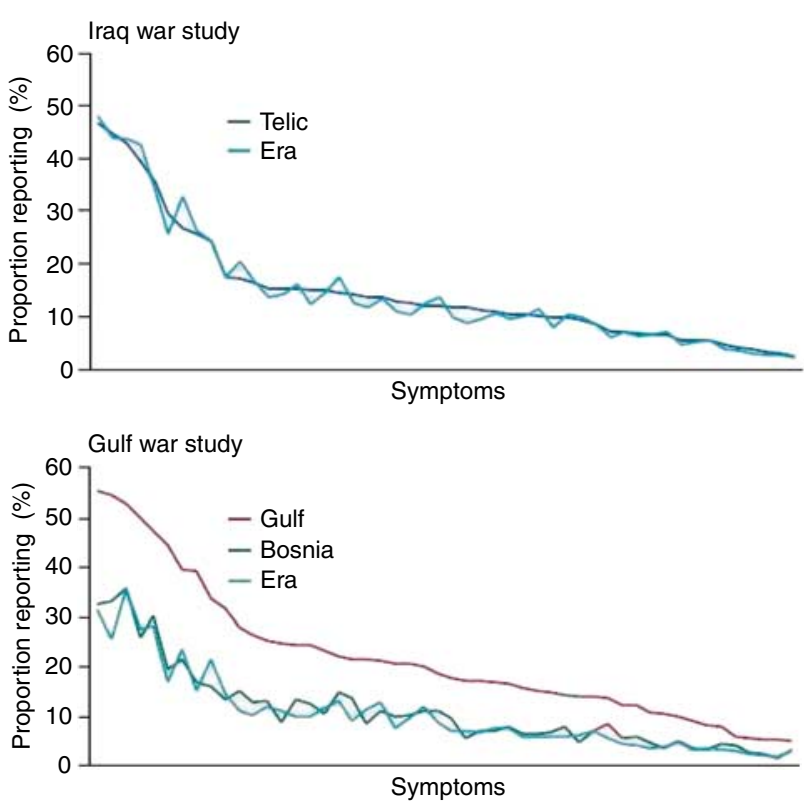

Figure 2 Graphical comparison of the Gulf health effects of the 1991 Gulf War and the Iraq War. ${ }^{30}$ These graphs are from studies carried out by King's College London after the Gulf War and the war in Iraq. The upper graph reports on a group of personnel who were deployed to Operation Telic (the UK codename for the Iraq War) and a group who were in the military at the time of the war but were not deployed. The graph below is the same as that shown in Figure 1. The graphs illustrate that there is no current evidence of an Iraq War syndrome and there is no difference between the Telic and Era groups. It is also evident that both groups now report symptoms at a frequency similar to the Gulf War group. This represents a general increase in symptoms reporting over recent years in Western communities.

The results are surprising: so far there has not been an increase in the same somatic symptoms that were apparent in the earlier Gulf War study. There has been a general increase in symptom reporting across the Armed Forces (Figure 2), unrelated to deployment, and which most probably reflects cultural changes in the reporting of symptoms and ill health that have been observed across society as a whole.

There is currently no evidence of a recurrence of 'GWS' arising in personnel returning from Iraq. ${ }^{71}$ Although this is welcome news for service personnel and their families, caution must be expressed. We do not know exactly when the health of those who were deployed to the 1991 Gulf War, and that of their comrades who were not, began to diverge. All we can say for sure is that the differences were clearly apparent six years after the conflict, although there were less clear suggestions that 'something' was amiss as early as 15 months post-conflict. However, it is still premature to assume that there will be no new Iraq war syndrome.

If history has indeed not repeated itself, what would that tell us about the possible causes of the Gulf War health effect? Any situations or exposures that were common to both conflicts cannot be blamed for the adverse health effects that arose after the earlier conflict. Both conflicts were 
fought on similar terrain against the same enemy. The UK Armed Forces used DU munitions in both conflicts. Likewise, anthrax vaccine was extensively administered to troops before both conflicts. During the conflicts, organophosphate pesticides continued to be used to reduce the threat of insectborne disease and pyridostigmine bromide tablets were issued in both conflicts, yet there was only a Gulf War health effect in the earlier and not the later conflict. Thus, it follows that none of the above now appear likely candidates for the Gulf War health effect.

Much has been written about stress as a cause of Gulf War illness. It is clear that the rates of psychiatric disorder have doubled in personnel who served in the Gulf compared with those who did not. ${ }^{31}$ There is little doubt that the current war in Iraq is proving to be a more long-lasting and difficult engagement than the 1991 conflict. In the USA, the rates of PTSD in Armed Forces are high and continue to increase after personnel return from Iraq. ${ }^{72}$ Simplistic explanations of Gulf-related illness as a sole manifestation of PTSD are likewise difficult to sustain given the considerably more hostile, prolonged, and dangerous situation in Iraq.

\section{Possible explanations for the Gulf War health effect}

Where does this information arising from the 2003 Iraq war and beyond leave us in finding explanations for the 1991 Gulf War health effect? We need to identify exposures or risk factors that first reflect the known epidemiology of Gulf War illness and also did not apply to the 2003 Iraq war (again assuming that no comparable 'Iraq War syndrome' will emerge). Any putative risk factor must therefore have affected US, Canadian, Australian, UK, and Danish forces, and within those forces, the exposure must also have acted on all the Armed Services with all the different occupations and roles equally at risk.

Medical countermeasures (MCMs) certainly fulfil the epidemiological risk profile, given that they were offered to all the Armed Services irrespective of the role. Yet that would still have to explain why, for example, the crew of the Canadian ship that did not use MCMs were subsequently just as vulnerable to ill health as those on the two sister ships that did. ${ }^{60}$ Or why Danish Gulf War soldiers, who received no MCMs at all because they were deployed on peacekeeping duties after the end of the formal hostilities, had almost identical rates and patterns of illness as US and UK forces. ${ }^{73}$

Likewise, it does not seem plausible to ascribe the differences in outcome to the changes in vaccine regimens between 1991 and 2003. The UK military authorities have not accepted that the vaccination programme in place in 1991 was a possible cause of the Gulf War health effect but nevertheless on a precautionary basis decided to change the vaccination programme before the invasion of Iraq. In particular, they decided to cease use of pertussis as an adjuvant with anthrax vaccine. Subsequent research, made easier by the improvement in medical record keeping since 1991, has shown convincingly that side effects of the anthrax vaccine in 2003 were short-lived and not associated with any longer term increase in symptomatic ill health. ${ }^{69}$ However, that does not prove that pertussis was the cause of the Gulf health effect. The UK was alone in using pertussis in 1991 but not alone in experiencing increased ill health in its personnel.

The clinical manifestations of service in the 1991 Gulf War may be influenced by a lack of trust veterans have in government officials' comments on aspects of the conflict. There are similarities between the experiences of Gulf War veterans and those of Vietnam veterans. ${ }^{74,75}$ The perceived government misinformation about Agent Orange was used to claim similar cover-ups and conspiracies, as was the Cold War legacy of experiments carried out on service personnel, often without consent. Governments on either side of the Atlantic have made misinformed statements on Gulf issues. For example, the US government misjudged the Khamisayah incident (an Iraqi arms dump considered to have held chemical weapons). ${ }^{76}$ The UK government made an inadvertently inaccurate statement to Parliament about the use of organophosphate pesticides. ${ }^{77}$ Both episodes led to further suspicion and occasional paranoia, both of which contributed to a media circus, and neither of which has helped the situation of Gulf veterans.

\section{Perception of threat}

So we must now consider other possibilities. There were indeed major differences between the Gulf and Iraq Wars, and these relate to the issue of the perception of the threat from Saddam Hussein's CBW arsenal, the so-called weapons of mass destruction. The threat from the Iraqi chemical and biological arsenal in 1991 was real and tangible. CBW agents had been used earlier against the Iraqi Kurds and in the IraqIran war. After the war, there was abundant evidence of the existence of a real CBW arsenal. This was widely known, and hence high importance was placed on the various MCMs adopted by the Coalition forces. Not surprisingly, fear of these unfamiliar but dreaded weapons was easily the most commonly endorsed concern among service personnel during the prolonged build-up to the actual war, the period covered by the term 'Desert Shield'. ${ }^{78,79}$ Because the threat did not actually materialise, memories soon faded. Few of our colleagues, for example, recall that Britain's National Health Service was mobilised to cope with an anticipated flood of casualties predicted to overwhelm the limited military health services and most UK civilian hospitals had not just plans prepared but wards vacated and staffed ready for the influx, which thankfully never materialised.

By 2003, both the US and UK Armed Forces continued to take the threat from CBW seriously and were unconvinced that Saddam really had degraded or destroyed his arsenal. But, the scale of medical preparations in the UK, for example, was very different to that in 1991, and there was no mobilisation of the NHS. Soon after the beginning of the conflict it became clear that for whatever reason the threat from CBW was not going to materialise. 
We therefore can speculate, and we accept this is speculation, that one of the principle differences between the Gulf War of 1991 and the Iraq war of 2003 has been in the perception of threat of CBW. On the one hand, the effect of the high levels of concern about this threat during the six months of Desert Shield, reinforced by over 4500 chemical alarms triggered during both Desert Shield and Desert Storm, cannot be underestimated. Concentrating on the substantial evidence that all the alarms proved negative (see http:// www.gulflink.osd.mil/library/osagwi_reports.jsp for full documentation) misses the point. Each alarm would increase anxiety as well as confirm that the risks were tangible, invisible, and potentially uncontrollable. Subsequent work has shown that a belief that one was exposed to chemical weapons has steadily increased, most particularly in US Gulf veterans, and is also the strongest single association for symptomatic ill health. ${ }^{40,80-82}$

\section{Media coverage}

A second possibility is that the extent and nature of the coverage of GWS itself served to amplify and reinforce symptoms and disability. There is now a vast and uncontroversial literature that what one thinks about an illness-its nature, cause, and likely outcome-has a powerful effect on the persistence and prognosis of the illness. This applies to many conditions, irrespective of any presumed physical or psychological aetiology, but is naturally particularly marked for the so-called 'unexplained' syndromes exemplified by Gulf War illness. Thus, the early stereotypes of GWS - mysterious, ill-defined, but linked to a series of potentially serious and frequently anxiety-provoking exposures, and alleged to be associated with tangible damage to the peripheral and/or central nervous system - may have become self-fulfilling. In keeping with extensive literature from other unexplained illnesses, it is not surprising that we found that believing one suffered from GWS was an independent and prospective predictor of a worse outcome. $^{83}$

\section{No 'Iraq War syndrome' but plenty of mental health problems}

Assuming that there is no new Iraq War syndrome does not mean there have been no serious or enduring health problems appearing in personnel returning from Iraq.

Starting with the UK Armed Forces, we found no increase in psychiatric disorders in regular personnel who have served in Iraq, at least up to $2006 .^{70}$ This does not mean that there were no cases of psychiatric injury, but that there was no excess compared with all the other deployments of the UK Armed Forces as represented by the non-Iraq control group. However, reservists who served in Iraq were indeed more likely to have symptoms suggestive of common mental health problems and/or PTSD compared with reservists who were not deployed. ${ }^{70}$ The explanation for this is not readily apparent and was not related to increased exposure to traumatic events. It may be partly explained by the way reservists are rapidly reintegrated back into civilian life after deployment. What was also clear was an observation that has been made repeatedly by us in other samples ${ }^{84}$ and by other researchers: ${ }^{85}$ that PTSD is not the most common mental health problem in the Armed Forces; that 'honour' belongs to alcohol problems and/or depression.

In contrast, US studies show a much higher rate of PTSD in their troops compared with UK Armed Forces. ${ }^{72}$ There are differences between the US and UK deployments that may help to explain this. The US Forces undertook more fighting and had more physical casualties, and this is indisputably associated with more psychological injuries. The US authorities deployed their troops for a year at a time, sometimes more, whereas UK military personnel usually have 4-6 month tours of duty. This means that US personnel had more opportunities for traumatic exposures and also their length of time away from home was itself a stressor. ${ }^{86}$ Other factors may also be at play. For instance, UK military personnel tend to be older than their US equivalents and there are also differences in the organisation of healthcare services once personnel leave the Armed Forces and return to civilian life.

\section{Post-conflict syndromes: an emerging health threat?}

It seems unlikely that any single cause of the Gulf War health effect will ever be discovered and it is heartening that for whatever reasons our Iraq War veterans do not as yet seem to be experiencing a repeat of GWS. We say 'as yet' because no one knows when the Gulf health effect was first detectable, only that it was present at a minimum of five years after the conflict.

The absence of a new 'unexplained' syndrome arising after the Iraq war may be a surprise, especially given the legacy of previous conflicts. ${ }^{69}$ However, as the term 'mild traumatic brain injury' emerges, it may be that the conflicts in Iraq and Afghanistan have still to get their 'signature' unexplained syndrome. ${ }^{87}$ What is indisputable is the dramatic increase in 'explained' syndromes that have arisen in, for example, US soldiers who have served in the Iraq conflict. Simply because PTSD, unlike GWS, has an accepted terminology and a reproducible case definition, it should not follow that it too counts as an 'unexplained' syndrome similar to all psychiatric disorders. As numerous critics have pointed out, the assumption that trauma has central importance in the aetiology of PTSD sits uneasily within the general atheoretical nature of psychiatric classification, in which syndromes are defined by symptoms, not aetiology. There is a considerable critical literature on the diagnosis of PTSD, its political as opposed to medical or research origins, and in particular how the assumption that trauma has a central role obscures many other factors that are also of aetiological importance. ${ }^{88,89}$

The rise, and it is a considerable and dramatic rise, in postconflict psychiatric disorders now being reported from the $\mathrm{USA}^{72}$ must be seen as evidence that post-conflict syndromes 
remain a major threat to the health of service personnel. As more and more nations either have already moved or are in the process of moving from large conscript or national service armed forces to smaller, better trained professional services, monitoring their health and their health concerns is becoming an increasing priority. Perhaps one of the enduring health legacies of the 1991 Gulf War has been the launch of longer term cohort studies of either the entire Armed Forces or large representative samples thereof, a process that has begun in the USA, Canada, the UK, Australia, the Netherlands, and elsewhere. Research and health surveillance are now seen as necessary for monitoring emerging health threats to provide empirical data and also to provide reassurance to service personnel, their families, the public, and the media.

\section{Acknowledgements}

We would like to thank all those military personnel from numerous countries who have given their time to allow researchers to investigate them so as to further our knowledge and to help their colleagues.

\section{Author contributions}

Both authors contributed equally to the development, intellectual concepts, and writing of this paper.

\section{Competing interest}

Neil Greenberg is a serving officer in the Royal Navy and Simon Wessely is the civilian consultant advisor in psychiatry to the British Army, an honorary and unpaid role. This paper has not been subject to any amendment or alteration by the Ministry of Defence. Simon Wessely is funded by NIHR Biomedical Research Centre for Mental Health, The South London and Maudsley NHS Foundation Trust and King's College London, The Institute of Psychiatry.

Provenance and peer review

Not commissioned; externally peer-reviewed.

\section{References}

1 Arneta MRG, Schlangen KM, Edmonds LD, Destiche DA, Merz $\mathrm{RD}$, Hobbs CA, et al. Prevalence of birth defects among infants of Gulf War veterans in Arkansas, Arizona, California, Georgia, Hawaii, and Iowa, 1989-1993. Birth Defects Res A Clin Mol Teratol 2003;67:246-60.

2 Hyams K, Hanson K, Wignall F, Escamilla J, Oldfield E. The impact of infectious diseases on the health of US troops deployed to the Persian Gulf during Operations Desert Shield and Desert Storm. Clin Infect Dis 1995;20:1497-504.

3 Lee H, Gabriel R, Bolton J, Bale A, Jackson M. Health status and clinical diagnosis of 3000 UK Gulf War veterans. JR Soc Med 2002;95:491-7.

4 Gray G, Gackstetter G, Kang H, Graham J, Scott K. After more than 10 years of Gulf War veteran medical examinations, what have we learned? Am J Prev Med 2004;26:443-52.

5 Joseph S. A comprehensive clinical evaluation of 20,000 Persian Gulf War veterans. Mil Med 1997;162:149-56.
6 Coker W, Bhatt B, Blatchley N, Graham J. Clinical findings for the first 1000 Gulf War veterans in the Ministry of Defence's Medical Assessment Programme. Br Med J 1999;318:290-4.

7 Kang H, Bullman TA, Macfarlane GJ, Gray GC. Mortality among US and UK veterans of the Persian Gulf War: a review. Occup Environ Med 2002;59:794-9.

8 Kang HK, Bullman TA. Mortality among U.S. veterans of the Persian Gulf War. N Engl J Med 1996;335:1498-504.

9 MacFarlane G, Thomas E, Cherry N. Mortality amongst United Kingdom Gulf War veterans. Lancet 2000;356:17-21.

10 MacFarlane G, Biggs A, Maconochie N, Hotopf M, Lunt M. Incidence of cancer among UK Gulf War veterans: cohort study. Br Med J 2003;327:1373-5.

11 Kelsall HL, Sim MR, Forbes AB, Glass DC, McKenzie DP, Ikin JF, et al. Symptoms and medical conditions in Australian veterans of the 1991 Gulf War: relation to immunisations and other Gulf War exposures. Occup Environ Med 2004;61:1006-13.

12 DeFraites RF, Wanat ER, Norwood AE, Williams S, Cowan D, Callahan T. Report, Investigation of a suspected outbreak of an unknown disease among veterans of Operation Desert Shield/ Storm, 123d Army Reserve Command, Fort Benjamin Harrison, Indiana, April, 1992. Epidemiology Consultant Service (EPICON), Division of Preventive Medicine, Walter Reed Army Institute of Research: Washington, DC, 15 June 1992.

13 The Iowa Persian Gulf Study Group. Self-reported illness and health status among Gulf War veterans. A population-based study. JAMA 1997;277:238-45.

14 Unwin C, Blatchley N, Coker W, Ferry S, Hotopf M, Hull L, et al. The health of United Kingdom servicemen who served in the Persian Gulf War. Lancet 1999;353:169-78.

15 Ismail K, Everitt B, Blatchley N, Hull L, Unwin C, David A, et al. Is there a Gulf War syndrome? Lancet 1999;353:179-82.

16 Everitt B, Ismail K, David A, Wessely S. Searching for a Gulf War syndrome using cluster analysis. Psychol Med 2002;32:1371-8.

17 Stretch R, Bliese P, Marlowe D, Wright KM, Knudson KH, Hoover $\mathrm{CH}$. Physical health symptomatology of Gulf War-era service personnel from the States of Pennsylvania and Hawaii. Mil Med 1995;160:131-6.

18 Kang HK, Mahan CM, Murphy FM. Illnesses among United States veterans of the Gulf War: a population-based survey of 30,000 veterans. J Occup Environ Med 2000;42:491-501.

19 Sim M, Kelsall H. Gulf War illness: a view from Australia. Philos Trans R Soc London 2006;361:619-26.

20 Barrett DG, Doebbeling BN, Clauw DJ, Reeves WC. Prevalence of symptoms and symptom-based conditions among Gulf War veterans: current status of research findings. Epidemiol Rev 2003;24:218-27.

21 Proctor S, Harley R, Wolfe J, Heeren T, White RF. Health related quality of life in Gulf War veterans. Mil Med 2001;166:510-19.

22 Voelker M, Saag K, Schwartz D, Chrischilles E, Clarke WR, Woolson RF, et al. Health-related quality of life in Gulf War era military personnel. Am J Epidemiol 2002;155:899-907.

23 Higgins EM, Ismail K, Kant K, Harman K, Mellerio J, Du Vivier AWP, et al. Skin disease in Gulf war veterans. Q $J$ Med 2002;95:671-6.

24 Horner RD, Kamins KG, Feussner JR, Grambow SC, HoffLindquist J, Harati Y, et al. Occurrence of amyotrophic lateral sclerosis among Gulf War veterans. Neurology 2003;61:742-9.

25 Rose M. Gulf war service an uncertain trigger for ALS. Neurology 2003;61:730-1.

26 Armon C. Occurrence of amyotrophic lateral sclerosis among Gulf War veterans. Neurology 2007;68:1083.

27 Weisskopf MG, O’Reilly EJ, McCullough ML, Calle EE, Thun MJ, Cudkowicz $\mathrm{M}$, et al. Prospective study of military service and mortality from ALS. Neurology 2005;64:32-7.

28 Committee on Gulf War and Health. Volume 6: Physiologic, Psychologic, and Psychosocial Effects of Deployment-Related Stress. National Academy of Sciences: Washington, 2007. 
29 Ismail K, Kent K, Brugha T, Hotopf M, Hull L, Seed P, et al. The mental health of UK Gulf War veterans: phase 2 of a two-phase cohort study. Br Med J 2002;325:576-9.

30 King's Centre for Military Health Research (KCMHR); A Ten Year Report. What has been achieved by a decade of research into the health of the UK Armed Forces?. King's College London: London 2006, http://www.kcl.ac.uk/kcmhr/information/reports/ kcmhr_10_year_report.pdf.

31 Stimpson N, Weightman AL, Dunstan F, Lewis G. Psychiatric disorders in veterans of the Persian Gulf War of 1991-a systematic review. Br J Psychiatry 2003;182:391-403.

32 McCauley L, Joos S, Lasarev M, Storzbacha D, Bourdette DN. Gulf war unexplained illnesses: persistence and unexplained nature of self-reported symptoms. Environ Res 1999;81:215-23.

33 Kroenke K, Mangelsdorff A. Common symptoms in ambulatory care: incidence, evaluation, therapy and outcome. Am J Med 1989;86:262-6.

34 Mayou R, Bass C, Sharpe M. Overview of epidemiology, classification and aetiology. In: Mayou R, Bass C, Sharpe M (eds) Treatment of Functional Somatic Symptoms. Oxford University: Oxford, 1995, pp 42-65.

35 Wessely S, Unwin C, Hotopf M, Hull L, Ismail K, Nicolaou V, et al. Is recall of military hazards stable over time? Evidence from the Gulf War. Br J Psychiatry 2003;183:314-22.

36 Greenberg N, Iversen A, Hull L, Unwin C, Destrange M, Wessely S. Vaccination records in Gulf War veterans. J Occup Environ Med 2003;45:219.

37 Murphy D, Hooper C, French C, Jones M, Rona R, Wessely S. Is the increased reporting of symptomatic ill health in Gulf War veterans related to how one asks the question? J Psychosom Res 2006;61:181-6.

38 Wegman D, Woods N, Bailar J. Invited commentary: how would we know a Gulf War syndrome if we saw one? Am J Epidemiol 1998;146:704-11.

39 Kroenke K, Price R. Symptoms in the community: prevalence, classification and psychiatric comorbidity. Arch Intern Med 1993;153:2474-80.

40 Haley RW, Kurt TL, Hom J. Is there a Gulf War syndrome? Searching for syndromes by factor analysis of symptoms. JAMA 1997;277:215-22.

41 Anon. Gulf War and Health: Volume 4: Health Effects of Serving in the Gulf War. Institute of Medicine, National Academies Press: Washington, 2006.

42 Haley RW, Hom J, Roland PS, Bryan WW, Van Ness PC, Bonte FJ, et al. Evaluation of neurologic function in Gulf War veterans. A blinded case-control study. JAMA 1997;277:223-30.

43 Haley RW. Gulf War syndrome: narrowing the possibilities. Lancet Neurol 2003;2:272-3.

44 Committee on Gulf War and Health. Gulf War and Health: Updated Literature Review of Sarin. National Academy of Science: Washington DC, 2004

45 Brown M. Toxicological assessments of Gulf War veterans. Philos Trans $R$ Soc London 2006;361:649-79.

46 Sharief M, Pridden J, Delamont R, Rose M, Unwin C, Hull L, et al. Neurophysiologic evaluation of neuromuscular symptoms in UK Gulf War veterans. A controlled study. Neurology 2002; 59:1518-25.

47 Davis L, Murphy F, Alpern R, Parks B, Blanchard M, Reda D, et al. Clinical and laboratory assessment of distal peripheral nerves in Gulf War veterans and spouses. Neurology 2004;63:1070-7.

48 Vasterling J, Brember D. The impact of the 1991 Gulf War on the mind and brain: findings from neuropsychological and neuroimaging research. Philos Trans $R$ Soc London 2006;361:593-604.

49 Fukuda K, Nisenbaum R, Stewart G, Thompson WW, Robin L, Washko RM, et al. Chronic multisymptom illness affecting Air Force veterans of the Gulf War. JAMA 1998;280:981-8.

50 Steele L. Prevalence and patterns of Gulf War illness in Kansas veterans: association of symptoms with characteristics of person, place and time of military service. Am I Epidemiol 2000;152: 992-1002.

51 Cherry N, Creed F, Silman A, Dunnd G, Baxtera D, Smedley J, et al. Health and exposures of United Kingdom Gulf War veterans. Part 1: the pattern and extent of ill health. Occup Environ Med 2001;58:291-8.

52 Gray G, Reed R, Kaiser K, Smith T, Gastanaga V. Self reported symptoms and medical conditions among 11,868 Gulf War era veterans. Am J Epidemiol 2002;155:1033-44.

53 Hotopf M, David AS, Hull L, Nikalaou V, Unwin C, Wessely S. Gulf war illness - better, worse, or just the same? A cohort study. BM] 2003;327:1370A-2A.

54 Ismail K, Blatchley N, Hotopf M, Hull L, Palmer I, Unwin C, et al. Occupational risk factors for ill health in Gulf veterans of the United Kingdom. J Epidemiol Community Health 2000;54:834-8.

55 Wolfe J, Proctor S, Duncan Davis J. Health symptoms reported by Persian Gulf War veterans two years after return. Am I Ind Med 1998;33:104-13.

56 Ford J, Campbell K, Storzbach D, Binder L, Anger K, Rohlman D. Postraumatic stress symptomatology is associated with unexplained illness attributed to Persian Gulf War military service. Psychosomatic Medicine 2001;63:842-9.

57 Carney CS, Voelker M, Woolson R, Thorne P, Doebbeling BN Women in the Gulf War: combat experience, exposures, and subsequent health care use. MilMed 2003;168:654-61.

58 McDiarmid MA, Squibb K, Engelhardt SM. Health effects of depleted uranium on exposed Gulf War veterans: a 10 year follow up. J Toxicol Environ Health Part A 2004;67:277-96.

59 Bland D, Rona R, Coggan D, Anderson J, Greenberg N, Hull L, et al. Urinary isotopic analysis in the UK Armed Forces: No evidence of depleted uranium absorption in combat and other exposed personnel in Iraq. Occup Environ Med 2007;64:834-8.

60 Anon. Health Study of Canadian Forces Personnel Involved in the 1991 Conflict in the Persian Gulf. Goss Gilroy Inc: Ottawa, 1998.

61 Davis L, Eisen SA, Murphy F, Alpern R, Parks BJ, Blanchard M, et al. Clinical and laboratory assessment of distal peripheral nerves in Gulf War veterans and spouses. Neurology 2004;63:1070-7.

62 Institute of Medicine. Gulf War and Health: Volume 1. Depleted Uranium, Sarin, Pyridostigmine Bromide, Vaccines. National Academy of Sciences: Washington, DC, 2000.

63 Hotopf M, David A, Hull L, Ismail K, Unwin C, Wessely S. The role of vaccinations as risk factors for ill-health in veterans of the Persian Gulf War. Br Med J 2000;320:1363-7.

64 Osman Y. Environmental surveys conducted in the Gulf region following the Gulf War to identify possible neurobehavioural consequences. Environ Res 1997;73:207-10.

65 Golomb B. Acetylcholinesterase inhibitors and Gulf War illness. Proc Natl Acad Sci USA 2008;105:4295-300.

66 Donta ST, Clauw DJ, Engel CC, Guarino P, Peduzzi P, Williams $\mathrm{DA}$, et al. Cognitive behavioural therapy and aerobic exercise for Gulf War veterans' illnesses: a randomized controlled trial. JAMA 2003;289:1396-404.

67 Hotopf M. Treating Gulf War veterans' illnesses-are more focused studies needed? JAMA 2003;289:1436-7.

68 Hyams KC, Wignall S, Roswell R. War syndromes and their evaluation: from the U.S. Civil war to the Persian Gulf War. Ann Intern Med 1996;125:398-405.

69 Jones E, Hodgins-Vermaas R, Mccartney H, Everitt B, Beech C, Poynter D, et al. Post-combat syndromes from the Boer War to the Gulf: a cluster analysis of their nature and attribution. $\mathrm{Br}$ Med J 2002;324:321-4.

70 Hotopf M, Hull L, Fear N, Browne T, Horn O, Iversen A, et al. The health of UK military personnel who deployed to the 2003 Iraq war: a cohort study. Lancet 2006;367:1731-41.

71 Horn O, Hull L, Jones M, Murphy D, Browne T, Fear NT, et al. Is there an Iraq war syndrome? Comparison of the health of UK service personnel after the Gulf and Iraq wars. Lancet 2006;367:1742-6. 
72 Hoge CW, Castro CA, Messer SC, McGurk D, Cotting DI, Koffman RL. Combat duty in Iraq and Afghanistan, mental health problems, and barriers to care. N Engl J Med 2004;351:13-22.

73 Ishoy $T$, Suadicani $P$, Guldager B, Appleyard $M$, Hein $H$, Gyntelberg F. State of health after deployment in the Persian Gulf: the Danish Gulf War Study. Dan Med Bull 1999;46:416-19.

74 Scott WJ. PTSD and Agent Orange-implications for a Sociology of Veterans issues. Armed Forces Soc 1992;18:592-612.

75 Wessely S, Freedman L. Reflections on Gulf War illness. Philos Trans R Soc London 2006;361:721-30.

76 Gray G, Smith T, Knoke J, Heller J. The postwar hospitalization experience of Gulf War veterans possibly exposed to chemical munitions destruction at Khamisiyah, Iraq. Am J Epidemiol 1999;150:532-40.

77 Lloyd A. Report of the Independent Public Inquiry on Gulf War Illness 2004, http://www.lloyd-gwii.com/report.asp.

78 Gifford R, Ursano R, Stuart J, Engel C. Stress and stressors of the early phases of the Persian Gulf War. Philos Trans $R$ Soc London 2006;361:585-91.

79 Marlowe D, Martin J, Gifford R. Observations and Initial Findings of the WRAIR Stress Evaluation Team: Operation Desert Shield: 22 September-6 October 90. Walter Reed Army Institute of Research: Washington, DC, 1990.

80 Nisenbaum R, Barrett DH, Reyes M, Reeves WC. Deployment stressors and a chronic multisymptom illness among Gulf War veterans. J Nerv Ment Dis 2000;188:259-66.
81 Riddle J, Brown M, Smith T, Ritchie EC, Brix KA, Romano J. Chemical warfare and the Gulf war: a review of the impact on Gulf Veterans' health. Mil Med 2003;168:600-5.

82 Stuart J, Ursano R, Fullerton C, Wessely S. Belief in exposure to chemical and biological agents in Persian Gulf War soldiers. J Nerv Ment Dis 2008;196:122-7.

83 Chalder T, Hotopf M, Hull L, Ismail K, Unwin C, David A, et al. Prevalence of Gulf War veterans who believe they have Gulf war syndrome: questionnaire study. $\mathrm{Br}$ Med J 2001;323:473-6.

84 Jones M, Rona RJ, Hooper R, Wessely S. The burden of psychological symptoms in UK Armed Forces. Occup Med (Lond) 2006;56:322-8.

85 Engel Jr CC, Ursano R, Magruder C, Tartaglione R, Jing Z, Labbate LA, et al. Psychological conditions diagnosed among veterans seeking department of defense care for Gulf war-related health concerns. J Occup Environ Med 1999;41:384-92.

86 Rona R, Fear N, Hull L, Greenberg N, Earnshaw M, Hotopf M, et al. The mental health consequences of 'overstretch' in the UK armed forces. Br Med J 2007;335:603-7.

87 Jones E, Fear NT, Wessely S. Shell shock and mild traumatic brain injury: a historical review. Am J Psychiatry 2007;164:1641-5.

88 Summerfield D. The invention of post-traumatic stress disorder and the social usefulness of a psychiatric category. $\mathrm{Br}$ Med $\mathrm{J}$ 2001;322:95-8.

89 Jones E, Wessely S. Post traumatic stress disorder: a paradigm shift in the conceptualization of psychiatric disorder. J Anxiety Disord 2007;21:164-75. 